\title{
La mirada hacia el sol naciente: vínculos entre las estéticas de Juan García Ponce y Jun'ichirō Tanizaki ${ }^{1}$
}

\section{The Gaze Towards the Rising Sun: Links Between the Aesthetics of Juan García Ponce and Jun'ichirō Tanizaki}

\author{
DAVID ISSAI SALDAÑA MONCADA \\ Universidad Nacional Autónoma de México, México
}

Resumen: En este trabajo se comparan las manifestaciones literarias del erotismo en De ánima (1984), del escritor mexicano Juan García Ponce, y La llave (Kagi 1956), del autor japonés Jun'ichirō Tanizaki. Con base en un acercamiento previo de García Ponce a la literatura japonesa, se plantea un análisis de los alcances del orientalismo en la perspectiva del narrador mexicano, enfocado particularmente en el diálogo entre visiones del erotismo con Tanizaki. Abordar la perspectiva luminosa del erotismo de García Ponce permite evocar la sombra que representa la estética de su homólogo japonés, pues ambas se abocan a la exploración del deseo con una mirada que desdi-

Recepción: 17 de septiembre de 2020. / Aceptación: 20 de mayo de 2021.

${ }^{1}$ Para la realización de este trabajo conté con el financiamiento del Programa de Becas Posdoctorales en la Universidad Nacional Autónoma de México, en el Centro Regional de Investigaciones Multidisciplinarias, campus Cuernavaca, Programa de Estudios de lo Imaginario, y fui asesorado por el Dr. Óscar Figueroa Castro. 
buja las convenciones sociales. El contraste entre las obras mostrará cómo la apertura directa hacia el otro desde el ámbito artístico es una forma de problematizar las dinámicas de recepción orientalistas en América Latina.

Palabras clave: orientalismo; erotismo; estética; Juan García Ponce; Jun'ichirō Tanizaki.

Abstract: This work compares the aesthetic manifestations of eroticism in Mexican writer Juan García Ponce's De ánima (1984) and The Key (1956), a book by the Japanese author Jun'ichirō Tanizaki. García Ponce's prior approaches to Japanese literature enable an analysis of the scope of Orientalism from the Mexican writer's perspective, focusing on the dialogue between Tanizaki's different visions of eroticism. The luminous perspective of García Ponce's eroticism evokes the shadow represented by Tanizaki's aesthetics, anchored in the exploration of desire and a gaze that blurs cultural distinctions and shows how the direct opening to the other from the artistic sphere challenges the strictly social Orientalist discourses in Latin America.

Keywords: orientalism; eroticism; aesthetics; Juan García Ponce, Jun'ichirō Tanizaki.

\section{Introducción}

Para los estudiosos de la obra de Juan García Ponce (Mérida, 1932-Ciudad de México, 2003), así como para el lector que se acerca a De ánima (1984), ha sido problemático precisar el papel que en ella juega la novela La llave (Kagi 鍵, 1956), del autor japonés Jun'ichirō Tanizaki (Tokio, 1886-Kanagawa, 1965). La relación entre ambos textos es aparentemente obvia si se leen de manera superficial las palabras del mexicano en la "Introducción" a De ánima: "He pedido prestada para escribir esta novela la óptica que utilizaron Pierre Klossowski en $\mathrm{La}$ revocación del Edicto de Nantes, Jun'ichirō Tanizaki en La llave" (García Ponce 1995, 9). Según esta declaración, el autor se ha 
limitado a emular una perspectiva, la del diario, y la presenta como una forma de complicidad. ${ }^{2}$ No obstante, bajo el mero reconocimiento de la influencia o de un vínculo intertextual, ${ }^{3}$ existe la intención de entrar en contacto con las letras japonesas o de establecer un diálogo con uno de sus autores más afamados.

La literatura mexicana no era un campo virgen en este sentido: los nombres recurrentes son los de José Juan Tablada, Octavio Paz y Sergio Mondragón, todos poetas estudiados; sin embargo, la atención centrada en el análisis de las referencias o los vínculos entre la narrativa mexicana y la japonesa es menor. A pesar del interés en México por la literatura japonesa durante la segunda mitad del siglo xx, su difusión estaba limitada por las condiciones que afectaban directamente su estudio, como menciona Atsuko Tanabe (2004, 57): "Creo que existen dos causas fundamentales: la primera, la falta de interés institucional y, segunda, por la falta de traductores auténticos, lo que quizás sea consecuencia de la primera". A este fenómeno sigue una respuesta de la crítica, que se enfoca no sólo en la poesía sino también en un periodo concreto: el modernismo, como lo muestran los estudios de Odile Cisneros (2002), Araceli Tinajero (2004), Georgina Whittingham (2008) y Seiko Ota (2014); sólo Guillermo Quartucci (1996) ha dedicado un trabajo a los narradores mexicanos y japoneses del mismo periodo. ${ }^{4}$

${ }^{2}$ Hasta 2019, los críticos dedicados a la narrativa de Juan García Ponce se limitaron a reconocer la obra de Tanizaki como un intertexto o influencia (Pereira 2019, 74; Rosado 2003, 124); sin embargo, no se ha realizado un análisis detallado de ambas novelas. En relación con las culturas asiáticas, sólo Juan Antonio Rosado ha vinculado la dimensión mística de la obra de García Ponce con las manifestaciones espirituales de India (101).

${ }^{3}$ En adelante recurriré a la terminología desarrollada por Gerard Genette en Palimpsestos $(1989,10)$. La indagación de este trabajo se da en torno a las tramas de los personajes, de modo que las categorías de Genette permiten describir la relación en general, para después detallar la expresión artística de García Ponce en relación con la novela de Tanizaki, sobre todo en la forma de presentar el erotismo.

${ }^{4}$ En los últimos años, la ampliación del conocimiento en torno a Tablada refuerza la percepción de la época modernista como aquella que congrega la mayoría de las relaciones intertextuales entre estas literaturas, aun a expensas de los estudios 
Ante este panorama, el presente trabajo busca profundizar en el ámbito narrativo, al abordar la presencia de la literatura japonesa en la obra de Juan García Ponce. Por ello, en la primera parte de este ensayo se retoma un contacto previo del autor con dicha literatura, desde el cual es posible reflexionar acerca de la formulación o la ausencia de una aproximación orientalista: la postura crítica de las interacciones culturales planteada por García Ponce oscila entre el conocimiento somero de Japón y el interés conceptual por lo artístico, y esto definirá la relación textual entre De ánima y La llave.

En la segunda parte, se trazan las confluencias de ambas novelas en su dimensión contextual, pero con especial atención al erotismo, pues éste constituye un eje interpretativo que encuadra las relaciones de los personajes de los textos frente al marco social. Con base en esto, en la tercera parte se desarrolla un análisis del diario y sus voces narrativas, donde el contacto erótico se erige como el espacio de experimentación de las nociones estéticas de Tanizaki y las reflexiones sobre arte y literatura de García Ponce. En la cuarta parte se hacen explícitos los puntos de encuentro entre ambas obras, que toman forma en el contraste de luz y sombra en la mirada de las parejas de narradores. Con base en este recorrido, es posible plantear cómo la estructura de los diarios y el valor del escrito íntimo superan la mera referencia intertextual al colocar a las mujeres en una posición propicia para autodescubrirse, más allá de su papel como objetos de deseo de la mirada masculina.

\section{Lectura y diálogo con Japón: la persistencia del orientalismo}

El contacto literario previo a la interacción declarada entre De ánima y La llave se encuentra en un libro de ensayos de

dedicados a la presencia de Japón en la obra de escritores como Octavio Paz (Asiain 2014) o narradores como Mario Bellatin (Arrieta Domínguez 2015, 207-268). 
García Ponce titulado Entrada en materia, publicado en 1968. En el texto "Akutagawa y la literatura occidental”, el mexicano estudia y valora la obra de Ryūnosuke Akutagawa, uno de los escritores fundamentales de la literatura moderna de Japón. El interés por la presencia de la literatura japonesa en el mundo y particularmente en México, así como la búsqueda de rasgos estilísticos compartidos en los cuentos de Akutagawa y la obra del propio García Ponce, provocan una atenuación de las particularidades de la cultura japonesa.

García Ponce $(1968,154)$ reconoce varias cuestiones al enfrentarse a este escritor: en primer lugar, admite el desconocimiento de "Oriente" en la época, lo cual condiciona su comentario sobre la literatura de Akutagawa; en segundo lugar, confiesa que sólo cuenta con una muestra relativamente breve de obras traducidas del autor, por lo que las valorará con un enfoque estilístico, lo cual limita también sus opiniones sobre el contexto artístico del autor (155-156); por último, señala posibles autores occidentales con los cuales se pueden comparar los cuentos de Akutagawa, de modo que acude a un gesto universalista con el fin de situarlo en la literatura mundial (155).

A pesar de la esforzada lectura de García Ponce, que evita caer en el comentario fácil o estereotípico, refiere una definición esencial de la estética japonesa, al decir que la obra de Akutagawa

es intrínsecamente japonesa en su gusto por el detalle, en el poder plástico de las descripciones, en las particularidades psicológicas, en el ambiente y la transcripción de las costumbres, y sólo se abre a lo universal, a través de su forma cerrada, por la naturaleza misma de los problemas que trata y la concepción del mundo que los determina (García Ponce 1968, 160).

Una visión como ésta da pie a pensar en la convergencia entre la información que el autor tiene a la mano sobre las manifestaciones artísticas del país del sol naciente -obtenidas 
seguramente a partir de la obra de Kazuya Sakai- ${ }^{5}$ y su concepción del arte literario, así como la consecuente postura que un creador debería tener ante la vida. Tanto la percepción del arte japonés como su noción de artista se relacionan con un "centro" constituido por escritores cuyas obras representan cabalmente criterios estéticos a partir de los cuales se vinculan más allá de las especificidades culturales. ${ }^{6}$

El problema del orientalismo surge entre estos procedimientos de lectura como un velo tenue que el propio García Ponce aparta sólo de forma parcial e inconsciente. Por un lado, la concentración en lo artístico no basta para aislar el hecho de que sus referentes literarios son mayoritariamente europeos; por otro, interpreta y aprecia el lenguaje del autor japonés con cierta precaución sobre los alcances de sus comentarios, como se observa en el uso reiterado de frases como "las muestras de esas obras que nos es dado conocer" (García Ponce 1968, 155); "al menos en las obras que conocemos" (156); "tal como nos lo deja ver la naturaleza misma y la extensión de su obra, podemos suponer que" (156), etcétera.

En ese sentido, la necesidad de retomar lo "intrínsecamente japonés” funciona como una generalización extraída de la visión que el propio Japón proyecta en relación con su arte desde principios del siglo xx, con los trabajos de Okakura Kakuzō (2018, 41-42) y la posición del país como actor privilegiado en el arte asiático, hasta la década de 1930 con la aparición de la teoría mingei (artesanía popular), moldeada por Sōetsu Yanagi en diálogo con la artesanía occidental, la cual generó una noción esencialista y minimalista de lo japonés (Kikuchi 2004, 7).

${ }^{5}$ Kazuya Sakai (1927-2001), pintor argentino de origen japonés, fue traductor y prologuista de Akutagawa, conocido además en el ambiente artístico mexicano de la época tanto por sus colaboraciones con Octavio Paz en Vuelta, como por sus libros de difusión.

${ }^{6} \mathrm{Al}$ mencionar a Mann, Joyce, Proust y Musil, García Ponce afirma que sus obras "fueron publicadas o empezaron a ser creadas en un tiempo paralelo al de Akutagawa, [y en ellas] encontramos no sólo ese abismo que 'separa el arte de la vida y se abre hasta el infinito', sino también una voluntad semejante de responder a él precisamente con el arte, con la realidad de la obra” (García Ponce 1968, 160). 
El asunto orientalista no responde aquí a la discusión difundida por Said mediante su libro Orientalismo, de 1975, en la que se plantea un momento específico del acercamiento y el estudio a las culturas asiáticas que buscaba hacer conscientes las relaciones de poder y los discursos hegemónicos como elemento fundamental entre Oriente y Occidente. ${ }^{7}$ En primer lugar, porque los rasgos orientalistas del análisis de García Ponce dependen de la ausencia de difusión, es decir, de la situación específica de México ante Japón en términos culturales y no de un lazo colonialista.

Como se sabe, la reflexión sobre el orientalismo dio un giro para redefinir la hegemonía y permitir el replanteamiento de los vínculos interculturales desde diferentes enfoques críticos. Primero, se cuestiona que existan "diferencias ontológicas" y "esencias" del otro en los modelos clásicos del orientalismo, a saber, las relaciones entre Europa y Medio Oriente (Sadiq 2000,230 ). Segundo, se enfatiza la heterogeneidad de la supuesta hegemonía al deconstruir sus componentes raciales, económicos y de género (Lowe 1991, 24; Lewis 1996, 17-18). En tercer lugar, se sitúa la discusión desde lugares de enunciación como América Latina, pues ponen en crisis la estabilidad de esas relaciones hegemónicas (Nagy-Zekmi 2008, 14).

Salvo por la reproducción discursiva de estereotipos europeos acerca de estas culturas - como la cuestión de lo "misterioso" o abiertamente exótico-, la posición de México se encuentra en la última de las tendencias numeradas, en la “periferia” (Taboada 1998, 287): hoy en día, las formas de interacción con Asia se teorizan como un mapeo global, con

7 Para Said, el orientalismo es "una visión política de la realidad cuya estructura acentuaba la diferencia entre lo familiar (Europa, Occidente, 'nosotros') y lo extraño (Oriente, el Este, 'ellos') [...] Tener una cierta libertad para relacionarse con el otro era siempre un privilegio del occidental, porque la suya era la cultura más fuerte; él podía penetrar, abarcar, dar forma y significado al gran misterio asiático" (Said 2008, 73). Es decir, se efectúa una "esencialización" del otro según ciertos criterios. Sin embargo, la crítica posterior demostrará que la categoría no se limita a una descripción tan sencilla de las interacciones culturales. 
un imaginario propio y una visión de la otredad como reconocimiento de la diferencia:

Lo que la literatura mexicana revela sobre la crítica orientalista de Said es que aún es relevante, pero sólo en tanto se piense más allá del problema de la representación y la restitución del otro en la literatura, para centrarse en cambio en la construcción de un imaginario geográfico y global bajo el capitalismo, con sus zonas de excepción y fronteras (Torres-Rodríguez 2018, 13; traducción mía).

A partir de esto, vale decir que el orientalismo de Ponce indica la persistencia de tres elementos que semejan esa tríada de personajes en sus novelas (Pereira 2019, 64). El primero es el orientalismo europeo, atenuado por su coincidencia con un segundo elemento: una visión de lo japonés digerida por los propios japoneses. Con lo expuesto hasta ahora, es claro que García Ponce conoce la cultura japonesa por esas dos vías: una larga relación de intermediarios europeos, a los que se suma, como algo ajeno, la versión orientalista de los propios japoneses sobre su cultura.

El tercer elemento es el orientalismo mexicano, constituido en relación con los elementos anteriores, y cuyo rasgo definitorio, como decíamos, es un flujo de información limitado: recordemos que solamente circulaban traducciones de Akutagawa por Kazuya Sakai, y que no había interés institucional (Tanabe 2004, 57), de modo que el conocimiento superficial que se tenía de la cultura japonesa propiciaba ese procedimiento común al acercarse a otra cultura: "esencializar" al otro.

No obstante, García Ponce acude al texto literario antes que a la crítica académica o editorial y no tiene la intención de encasillar a Akutagawa, ya que lo que prima en su análisis es una lectura propia y no tanto esas ideas previas sobre lo japonés. Puede afirmarse que la postura del mexicano denota ya el reconocimiento de un valor vinculado a las cimas de la literatura mundial, desde una relación jerárquica que no contempla criterios ajenos a lo artístico. La opinión de García Ponce es positiva en tanto la "construcción de mundos" de 
Akutagawa coincide con las búsquedas de otros tantos escritores reconocidos.

Ahora bien, entre el ensayo sobre Akutagawa y la novela $D e$ ánima median 14 años en los que el autor mexicano ha madurado una estética centrífuga: autorreflexiva y definida como un arte que se concibe autónomo frente a la realidad, estructurado en torno al erotismo como actividad humana reveladora de una realidad profunda. ¿Qué sentido tiene asomarse otra vez a la literatura japonesa? ¿Qué es lo que retoma García Ponce de la literatura de Tanizaki?

\section{Erotismos y estéticas: entre lo público y lo privado}

El diálogo literario asumido por el mexicano se caracterizará entonces por la presencia de un orientalismo que no se adhiere del todo al enfoque europeo, como se observó en el texto de Akutagawa, pero a la vez está marcado por una visión "estable" de la estética japonesa, difundida como "lo esencial" por los propios japoneses. La relación entre De ánima y La llave también se configura desde esta lectura artística universalista, en la que el autor mexicano reconoce el valor de la literatura de Tanizaki sin cargar de sentido las peculiaridades socioculturales que refleja la obra del japonés, sino con un horizonte de expectativas meramente conceptual, enfocado en una abstracción de lo erótico.

Desde este punto de vista, es posible decir que la relación entre las novelas es, en primer lugar y según lo declara el propio García Ponce, architextual, en tanto la obra de Tanizaki le antecede y aporta un modelo genérico - el de la novela de diario- compartido con el texto de Klossowski. La inclusión de Tanizaki responde a una estrategia erótica que ambos desarrollarán en sus novelas, como se verá en el análisis posterior: la cultura japonesa funge como un tercero "desde fuera" entre dos escritores (el propio García Ponce y Klossowski) de la tradición occidental. La forma del diario aporta no únicamente una 
pauta estructural, sino también rasgos adecuados para explorar literariamente el erotismo; por lo tanto, De ánima resulta ser un hipertexto (Genette 1989, 17-18) en relación con el proceso erótico de ocultamiento-desvelamiento de la interioridad de los personajes. Esta dinámica es la del deseo erótico, y se da mediante la visión o la contemplación del otro, plasmada en confesiones íntimas cuya naturaleza desafía la moral, síntesis de las estructuras sociales más anquilosadas.

Tanto Tanizaki como García Ponce encuentran en la representación de la vía erótica los elementos más marcados de sus estéticas, la luz en el caso del mexicano, y la sombra en la obra del japonés, en constante diálogo con sus contextos socioculturales. Para Georges Bataille, el erotismo constituye:

Uno de los aspectos de la vida interior del hombre. En este punto solemos engañarnos, porque continuamente el hombre busca fuera un objeto del deseo. Ahora bien, ese objeto responde a la interioridad del deseo. La elección de un objeto depende siempre de los gustos personales del sujeto [...] El erotismo del hombre difiere de la sexualidad animal precisamente en que moviliza la vida interior. El erotismo es lo que en la conciencia del hombre pone en cuestión al ser [...] La actividad sexual de los hombres no es necesariamente erótica. Lo es cada vez que no es rudimentaria, cada vez que no es simplemente animal (Bataille 1997, 33).

El erotismo es una forma de manifestar el deseo carnal, centrada en el goce y no en la reproducción, poseedora de un lugar tal en la vida humana que resulta una estancia reflexiva imprescindible para la propia comprensión. Este tipo de discurso en torno al erotismo, en un nivel casi exclusivamente conceptual, también es compartido por Jean-Luc Marion, quien ve la interacción erótica como una vía alternativa a la determinación lógica y autónoma de lo racional:

Somos en tanto que nos descubrimos siempre ya presos en la tonalidad de una disposición erótica -amor u odio, desdicha o felicidad, goce o sufrimiento, esperanza o desesperación, soledad o comunión- y que 
no podemos pretender nunca que alcanzamos una neutralidad erótica de fondo sin mentirnos a nosotros mismos [...] el hombre se revela a sí mismo por la modalidad originaria y radical de lo erótico (Marion 2005, 13-14).

Y aún más: "amar pone en juego mi identidad, mi ipseidad, mi fondo más íntimo en mí que yo mismo” (16). Por lo tanto, el erotismo se posiciona como factor de suma importancia para entender la dimensión de crítica social en La llave y De ánima, pues a partir de la configuración de identidades masculinas y femeninas, en fuerte tensión con el contexto social, se pueden observar los efectos de nociones estéticas en apariencia desligadas de lo cotidiano, pero que dan forma al autodescubrimiento de los personajes femeninos.

Vale la pena mencionar algunos aspectos contextuales compartidos por La llave y De ánima, pues revelan cómo el tratamiento de lo erótico tiene como trasfondo la consagración de perspectivas largamente trabajadas. En el caso de Tanizaki, La llave es una de sus últimas novelas, publicada tras la monumental Las hermanas Makioka (Sasameyuki 1943-1948), con la que se cerró una etapa de retorno a la cultura tradicional japonesa, en respuesta a un primer periodo decadentista, asociado a la presencia de elementos occidentales. ${ }^{8}$ La segunda etapa creativa se articula a partir del famoso ensayo El elogio de la sombra (In'ei Raisan), de 1933, en el que Tanizaki vertió sus impresiones sobre el proceso de modernización de Japón y el valor de sus tradiciones frente a las nuevas tecnologías. Sus pesquisas lo llevaron a establecer una diferencia central entre la cultura japonesa y la occidental, a saber: la predilección de los nipones por la oscuridad y la sombra, en contraste con la luz y el brillo que atrae a los occidentales:

${ }^{8}$ Sadami Suzuki $(1996,30)$ analiza la crítica a la cultura japonesa ejercida por Tanizaki, sobre todo en las primeras dos décadas de su producción, acaso el periodo más desatendido por los estudiosos, que lo relegan a la categoría de erogurunansensu -abreviación y combinación japonesa de las palabras inglesas "eroticism", "grotesque" y "nonsense" - sin abordar la compleja dinámica de revisión de lo occidental y la propia tradición que llevará al ensayo de 1933. 
No es que a nosotros nos desagraden por principio todos los objetos que brillan, pero preferimos la luz velada que parece partir de dentro a lo que resplandece sólo en su superficie [...] Frente a los occidentales, dispuestos siempre a exponer a la luz la mugre y eliminarla de raíz, los orientales la atesoramos, la idealizamos en sí misma, aunque así dicho pueda sonar a excusas de mal perdedor, y la fatalidad nos lleva a amar las cosas que llevan esa mugre humana, esa tizne, o bien esas otras que están sucias de lluvia, de viento, así como tonalidades y brillos que nos hacen pensar en todo lo anterior (Tanizaki 2018, 37-39).

Además de la apreciación de la sombra y los claroscuros, que analizaré más adelante, otro de los elementos más destacados del ensayo es el balance estético entre lo "japonés” y lo "occidental", como menciona Ken K. Ito:

La carrera tardía de Tanizaki también fue bendecida en tanto la experiencia de la guerra y la derrota lo dejó relativamente intacto. A diferencia de muchos otros escritores, no cargó el estigma de haber apoyado a las autoridades en tiempos de guerra. Tampoco compartía el particular sentido de pérdida, contaminado por el desarraigo y la humillación que sentían los escritores jóvenes cuyas carreras se iniciaron en un Japón de posguerra, irreconocible debido a la derrota. Hasta cierto punto, Tanizaki ya había confrontado y resuelto la situación a la que se enfrentaban los hombres más jóvenes. Había logrado en su ficción una respuesta artística y emocionalmente significativa a la pérdida de una cultura; con Sasameyuki había demostrado que un mundo pasajero podía llorarse y fijarse a la vez y para siempre (1991, 210-211; traducción mía).

En su etapa madura, Tanizaki exorcizó para sí el problema más acuciante del Japón moderno: el de la identidad entre sus tradiciones y la implementación de conocimientos y tecnologías occidentales, presuntos heraldos de la destrucción de la forma de vida japonesa. Tanto la tendencia a las sombras como esta síntesis cultural se manifestarán en el erotismo de La llave como un impulso masoquista, explorado en obras anteriores, mediante el cual el individuo proyecta sus deseos confrontados con las reglas de la sociedad: 
Tanizaki muestra que este sufrimiento es el producto de la occidentalización exitosa de Japón, y que lo que hace que sus ensayos sean tan interesantes es la forma en que documenta ese sufrimiento en pequeñas e insoportables bolsas de autodesprecio nacional metidas intermitentemente en su propia escritura sobre la cultura [...] Lo que Tanizaki logra al poner el dolor y su antídoto fetichista lado a lado es reescribir el "esencialismo" del culturalismo japonés como una respuesta paliativa a la crisis de la nación y no como una identidad pura o previa (Long 2009, 5; traducción mía).

Así, la crítica a la rígida estructura social japonesa va más allá del problema de la modernización, pues en el seno de ésta, lo colectivo y lo individual están confrontados en su nivel más íntimo, el erótico, como uno de los componentes más relevantes para la estabilidad social y la construcción de identidad -sobre todo la femenina-, justo como lo postulan Bataille y Marion.

Por otro lado, De ánima se presenta como un texto capital en la obra de García Ponce, pues afianza su perspectiva estética en torno a la representación literaria del erotismo en relación con obras anteriores. Al respecto, el autor mexicano afirma en la introducción a la novela:

Ahora en vez de un gato, "el gato" es ya una obra. Su argumento y sus personajes son una ficción que se hace aparecer a través de la realidad del argumento y los personajes de esta nueva obra de ficción. Las dos obras anteriores dialogan de este modo con la presente novela del mismo modo que los personajes de ésta dialogan entre sí a través de su relación amorosa, de sus respectivos diarios secretos y de la relación que la existencia de El gato crea entre ellos $(1995,10)$.

Centrado en lo literario, confronta el contexto social de manera similar a la que estableció Tanizaki: junto a sus compañeros de generación, García Ponce se posicionó a favor de la difusión de ideas artísticas y literaturas extranjeras, en oposición a grupos que defendían un nacionalismo cerrado. ${ }^{9}$ Para él, la

${ }^{9} \mathrm{Al}$ respecto vale la pena recordar los conflictos entre el grupo de García Ponce y otros actores culturales que llevaron a su salida de la Revista de la Universidad de México, 
oposición generalizada entre la realidad y la literatura (como en su lectura de Akutagawa) deriva en una postura del arte y el erotismo como formas de ingresar a realidades inaccesibles desde la vida cotidiana:

El mundo narrativo de Juan García Ponce pretende que el protagonista sea representado por el artista, quien desprovisto de escrúpulos aparece como el buscador del equilibrio entre vida y espíritu, o bien, como la víctima de su ausencia [...] La figura del artista está representada con las características vanguardistas antes mencionadas: la pretensión de adelantarse a su tiempo, la de rechazar valores de la sociedad, la de ser un visionario, la de estar dispuesto a llevar las relaciones interpersonales a facetas nuevas, la de combatir el nihilismo y el solipsismo (De la Peña 2003, 44).

Desde este punto de vista, De ánima tiende un puente con La llave al distanciarse del peso de la cultura nacional: sitúa a sus personajes en el territorio del deseo, donde desarrolla su interioridad y problematiza la influencia de lo social en el arte, incluso en un terreno metafísico:

García Ponce -al igual que Bataille y Klossowski- parte de la ausencia de centro, de la inexistencia de Dios o de la Razón, del sinsentido de la realidad -hecho que el autor yucateco no asume desde la metafísica, sino desde la estética-, y asimismo sustituye ese centro por la asistematicidad sin centro del Arte, donde necesariamente interviene el logos, no como verdad, sino como engaño (Rosado 2003, 122).

Así, ambas novelas se enlazan mediante la presentación de un marco cuyo valor depende de las acciones de los personajes, pues éstos representan esas vías eróticas en las que la imagen pública contradice aparentemente al deseo, pero, en realidad,

resumidos en la reflexión de Huberto Batis $(1984,140)$ sobre el ataque del nacionalismo mexicano: "Tocó al nacionalismo ramplón, demagógico y populista intentar destripar a mi gente de letras [...] en aquel río revuelto, Gastón García Cantú implantó, desde Difusión Cultural de la Universidad Nacional, la represión de todo arte, literatura y pensamiento crítico que no se ocupara en contarle las lentejuelas a la china poblana”. 
dicha imagen se erige como una visión primera que impulsa la interacción del erotismo. En ese sentido, la poca atención dispensada al espacio urbano muestra cómo es la interioridad de los personajes, y no los hechos sociales, lo que moviliza las acciones: a pesar de estar ubicada en Ōsaka, el espacio exterior al hogar o al cuarto íntimo no es determinante en La llave; de igual forma, no hay un recorrido significativo por la Ciudad de México en De ánima. Con base en la dinámica del diario, tanto Tanizaki como García Ponce trazan un espacio de experimentación profundo que supera el ámbito social.

Ahora bien, ¿cómo interactúan los protagonistas? En los dos casos se fraguan triángulos eróticos, generalmente compuestos por dos hombres y una mujer, en los que ésta cobra un papel central o, mejor dicho, lo tiene desde el inicio y lo descubrirá poco a poco. Esos tríos se conducen al límite del placer que, en el caso de las mujeres, resulta en una cuestión benéfica; en el caso de los hombres, el paroxismo tiene un desenlace mortal, y su sentido varía en ambos textos.

El erotismo es el eje estructural y cada autor elige vías distintas para explorarlo: en el caso de García Ponce, hay una búsqueda marcada por la revelación y la luz; para Tanizaki, en cambio, La llave representa una oportunidad para mostrar las sombras del deseo, emanadas de la incapacidad para mostrarse ante el otro. Veamos cómo se imbrica la visión de Tanizaki con la de García Ponce.

\section{La dinámica de los diarios: la sombra del deseo}

La relación entre lo público y lo privado es un punto de partida para observar las interacciones eróticas. El diario a dos voces de La llave presenta a un matrimonio - un profesor universitario del que no se menciona el nombre, e Ikuko, su esposa- cuyo rasgo principal es el distanciamiento en el terreno sexual: él tiene inclinaciones fetichistas, mientras que ella se muestra tradicional en la cama, aunque ávida; el profesor 
es 10 años mayor que Ikuko y admira su belleza; ella siente repulsión, no sólo por la vejez de su marido, sino también por su apariencia física y sus fetiches. La trama abarca seis meses de un año no especificado, en los que la incompatibilidad de la pareja produce un viraje en la escritura del diario del profesor y, consecuentemente, motivará el diario de Ikuko: "Me impulsa a escribir la frustración de no tener jamás la oportunidad de hablar con ella de nuestros problemas sexuales. A partir de ahora, tanto si lee estas páginas como si no, supondré que lo hace y que le estoy hablando de una manera directa" (Tanizaki 2016, 9). ${ }^{10}$

El elemento que articula toda la novela de Tanizaki es la complicidad de las apariencias: el profesor describe a su mujer como una persona sigilosa, que reniega de su verdadero carácter, pues se muestra recatada, pero es fisgona; aparenta ser tradicional, pero es sexualmente insaciable. A partir de estas oposiciones, derivadas de su incomunicación, el profesor asume que su esposa lee su diario, aunque ella lo niegue, y, aún si no lo hace, lo hará. Para ello, deja a la vista la llave del cajón en el que lo guarda: ofrece el diario de forma subrepticia. La privacidad del diario se simula para entablar una forma de comunicación "más allá" de la cotidianeidad matrimonial. De aquí el título de la novela: la llave representa la invitación a un juego de ocultamiento y descubrimiento en torno a los papeles tradicionales de marido y mujer, bajo los cuales anidan deseos desbocados.

Los diarios representan visiones contrapuestas: el discurso del profesor conlleva una intimidad propia desde la que le ha-

${ }^{10} \mathrm{Al}$ ser el interés central de este artículo la lectura de García Ponce sobre Tanizaki, citaré la traducción más reciente de La llave al español. Lo más probable es que García Ponce haya leído la traducción al inglés de 1960 a cargo de Howard Hibbett (Tanizaki 1960). Ya que el escritor mexicano se acerca por esta intermediación, es imposible que repensara los rasgos del original japonés, como el recurso formal para diferenciar los diarios con el uso de hiragana en el caso de Ikuko, y de katakana en el del profesor, así como inflexiones propias del habla femenina (onnakotoba) (Tanizaki 2015). Éste es otro factor por considerar, muy parecido a las condiciones de su lectura de Akutagawa. 
bla a su esposa; el diario de Ikuko se origina desde el discurso sexual de su marido, nace con el fin de procurarse un espacio en el cual verter sus propios deseos. Sólo después de notar que su marido la descubre escribiendo, Ikuko finge no saber que él lee lo que escribe y pretende darle continuidad a la propuesta subrepticia de diálogo. Ella utiliza al profesor, a pesar de que él piense lo contrario, pues es él quien se entrega a las situaciones sexuales más extenuantes, creyendo que tiene el control. Así, el esfuerzo escritural de cada uno tendrá como motivo la satisfacción de sus deseos, como lo muestra este fragmento del diario de Ikuko:

Siento un profundo desagrado por mi marido, pero lo amo casi con la misma intensidad. Por mucho que él me repugne, jamás me entregaré a otro hombre. De ninguna manera podría abandonar mis principios que me obligan a la fidelidad. Pese a lo mucho que me exaspera su manera morbosa y repulsiva de hacer el amor, es evidente que sigue enamorado de mí y siento que, de alguna manera, he de responder a su afecto [...] Si realmente me quisiera, debería aprender a satisfacerme. No obstante, confío en que recuerde que no puedo soportar esos innecesarios hábitos juguetones que, lejos de estimularme, dan al traste con mi buena disposición de ánimo. Mi naturaleza siempre me inclina hacia las costumbres tradicionales, y quiero realizar el acto ciegamente, en silencio, bajo gruesos edredones, en el dormitorio a oscuras (Tanizaki 2016, 16).

A pesar de lo que puede aparentar, debido a la poderosa imagen de discreción y recato que arroja la tradición cultural japonesa, en La llave lo social funge como el marco que motiva la perversión de lo oculto (Ito 1991, 19). En la superficie, lo que Ikuko busca es lo tradicional y, al hacerlo, también acata su posición como mujer. Sin embargo, la repulsión que siente por su marido es tal que no puede evitar pensar en otras soluciones, entre las cuales no se encuentra la discusión de sus problemas sexuales. Al contrario, reclama atención de parte de su marido, quien pronto leerá su diario y entenderá que no podrá satisfacerla solo, por lo cual incorporarán a un tercero de manera "natural" y "discreta". 
Así, la aparición de uno de los personajes secundarios se vuelve un factor determinante: Kimura, subalterno del profesor en la universidad, funge como el "tercero", papel que coincide con el de los personajes de García Ponce. Gracias a él, el profesor recobra su apetito sexual, al establecer una dinámica - que llega a ser diaria- en la que Kimura visita al matrimonio y se emborrachan juntos hasta que Ikuko pierde el conocimiento en la bañera; Kimura auxilia al profesor para cuidar a Ikuko, se retira y el marido aprovecha el estado etílico de su esposa para explorar sus fetiches en ella, además de satisfacerla. Sin embargo, el acto se repite constantemente y Kimura se vuelve necesario para que el profesor mantenga su vitalidad gracias a los celos, lo cual abre la posibilidad de que Kimura e Ikuko entablen una relación independiente (Tanizaki 2016, 18).

Esta dinámica supone una visión mordaz del deseo, en la que el sexo como posible acto ritual, discontinuo (Bataille 1997, 16), pierde sentido a causa de la ansiedad del profesor; el exceso provoca que el acto erótico en sí, la resistencia a la desnudez fácil (Marion 2005, 135-136), se concrete en Kimura e Ikuko, ya que son ellos quienes observan, imaginan y esperan hasta poder intimar. Si bien Ikuko está consciente de las acciones de su marido mientras está borracha, su conciencia se genera desde las sensaciones y el placer que encuentra en el ensueño del alcohol:

Entonces tuve la ilusión de que abrazaba al señor Kimura. Pero ¿es acaso “ilusión” la palabra apropiada? ¿No sugiere algo nebuloso que flotaba en la atmósfera y que desaparecería de un momento a otro? Lo que vi y sentí no era tan intangible, no era sólo la ilusión de abrazarle. Incluso ahora la sensación pervive en mis brazos y muslos. Es totalmente distinta a la del abrazo de mi marido (Tanizaki 2016, 28).

El profesor transgrede la voluntad de Ikuko al grado de explorar su cuerpo con una luz fosforescente, que no es un detalle menor si se tiene en cuenta que Ikuko siente repulsión por su marido debido a su tez "suave y brillante" (Tanizaki 
2016, 13). En realidad, es ella quien reconoce en estos actos una oportunidad única para concretar su fascinación por Kimura, quien posee una belleza de actor americano (15) con rasgos dignos de El elogio de la sombra, pues su piel "tiene una lustrosa pátina de frescura, una tonalidad rosada bajo el blanco" (68), como los objetos descritos en el famoso ensayo. Kimura encarna el balance de estas dos caras del Japón moderno: es "lo deseable" entre lo nuevo y lo tradicional, de modo que lo social se sintetiza en un personaje literario, objeto del deseo femenino.

Para complicar el panorama, la presencia del "tercero" activo y silente se desplaza hacia Toshiko, la única hija del matrimonio y prometida del señor Kimura. Si bien la relación de esta joven pareja parece discreta, normada por las etiquetas de decoro de la sociedad japonesa, en realidad está basada en una dimensión auténticamente perversa por parte de ambos. La mirada de los terceros entra en pugna: los fetiches del profesor son burdos si se comparan con la forma en que Toshiko ayuda a su madre a encontrarse con Kimura en su departamento de soltera. A partir de ese primer encuentro, Ikuko y Kimura se frecuentarán al grado de cambiar el escenario de las borracheras, de la casa familiar al departamento de Toshiko. Todo esto provoca más celos, hasta deslizar el papel del "insaciable" hacia el profesor:

El fermento de pasión que acompaña a los celos, los impulsos sexuales avivados por la contemplación arrobada de su desnudez... todo esto me hace perder el dominio de mí mismo y me lleva a la locura. Ahora soy yo el insaciable. Una noche tras otra me sumerjo en éxtasis inauditos. Es inevitable que me sienta agradecido por mi dicha, pero al mismo tiempo tengo el presentimiento de que terminará, de que algún día deberé pagar por ella, de que esta excitación me va acortando la vida (Tanizaki 2016, 46).

La extenuación es tal que escribirá una llamada de auxilio, pues pide a Ikuko abandonar esa naturaleza insaciable, sólo compensable mediante los celos desmedidos que tanto lo ex- 
citan. Pero Ikuko no se detiene y él tampoco, hasta que sufre una apoplejía por la tensión y el cansancio excesivo. Al final, el profesor muere debido a que Toshiko confirma la relación sexual de Kimura y su madre. Tras la muerte de su esposo, Ikuko sopesa lo acontecido al comparar de forma crítica ambos diarios: primero recuerda cómo empezó a escribir su diario, después confiesa que leía el de su marido y, al final, asume su propio deseo, siempre a la sombra de lo narrado:

Durante todo marzo había escrito que defendía tenazmente la "última raya", y que hacía cuanto estaba en mi mano para convencer de ello a mi marido. En realidad, el 25 de marzo cayó la última defensa "delgada como el papel" [...] Me había dicho a mí misma que me comportaba como una esposa leal, incluso desde un punto de vista moral anticuado. Pero entonces me quité la máscara del engaño y admití sinceramente que estaba enamorada de Kimura (Tanizaki 2016, 113).

El proceso es tortuoso, acelerado por la exaltación de los encuentros sexuales; asaltada por su marido, después enamorada de Kimura, Ikuko se autodescubre como una mujer cuyos deseos sexuales son satisfechos apoyándose en el fingimiento, pues, a pesar de todo, Kimura se casará con Toshiko, lo que deja abierta la posibilidad de un triángulo sombrío, aún más "perverso" que los fetiches del finado profesor.

\section{La luz estética del erotismo}

Como veremos a continuación, un análisis comparativo de las estéticas eróticas muestra que los vínculos entre las obras exceden el préstamo genérico, sobre todo si se destaca la relación de los personajes principales de De ánima, Paloma y Gilberto. A diferencia de los de Tanizaki, estos no establecen un lazo familiar entre sí; es más, su relación se configura desde una absoluta libertad en la que ninguno de los dos se siente obligado por convenciones frente al otro (Pereira 2019, 65). Dicho aspecto se confirma al revisar las descripciones de los 
lugares, las personas y las expectativas sociales que Paloma y Gilberto frecuentan: siempre las comentan como desviaciones que, para el lector, constituyen pausas forzosas a fin de balancear la intensidad erótica.

La dinámica de los diarios también es distinta. Gilberto comparte con el profesor de La llave la posición de hombre educado, ambos dan clases de literatura en una universidad, pero el personaje mexicano tiene una relación particular con su diario, pues García Ponce decide mostrar al lector reflexiones de otro tipo, mayoritariamente artísticas, incluso antes de que se mencione a Paloma, lo cual contrasta con el diario del profesor japonés, del cual sólo conocemos la parte final. Si bien la diferencia de edad respecto a sus parejas no es un factor en común (no se señala la edad de Gilberto), los hombres coinciden en la necesidad de explorar sus fetiches, entre los que se encuentra incluir a terceros en su relación y, cuando creen seguir los designios de sus propios deseos, en realidad posibilitan el cumplimiento de los de sus parejas.

En cuanto a la estructura del diario, vale señalar que si la reflexividad en La llave se sustentaba mediante la duda sobre el estatuto de verdad del diario del otro, el aspecto ensayístico de De ánima, con las ideas de Gilberto sobre el arte, facilita que los diarios de cada personaje se conviertan en instancias reflexivas sobre su identidad a partir de las experiencias eróticas. Esto resulta en una forma discursiva particular: la reflexividad se erige como un método básico para filtrar sucesos cotidianos e incorporar ideas o comentarios fuera de la anécdota. Se aspira a representar el flujo de la conciencia, pero no es verosímil que todo lo escrito sea verdad; lo íntimo proyecta inseguridad ante la enunciación subjetiva. En ese sentido, es importante considerar el acceso al diario del otro en las novelas, pues en ello radica un matiz del proceso de reconocimiento del deseo en Paloma e Ikuko: enlazadas mediante la exposición y el ocultamiento, es decir, la luz y la sombra, ambas pensarán más allá del supuesto papel dominante de los hombres, pero la comunicación con ellos será diferente. 
En contraste con Ikuko, Paloma es una mujer poco apegada a las normas sociales. Aunque éstas operan como formas de presión sobre ella, decide encararlas en su manifestación más recurrente: la culpa, con lo cual también abre paso a la crítica del papel femenino en el acto erótico:

Si de algo me arrepiento es de lo que vino después. Armando logró que en algunas ocasiones me sintiera culpable. ¿Culpable de tener diecisiete años y ser tan bella, de conocer mi desnudez y saber buscar mi propio placer? Eso es lo único que no debe aceptarse. Estoy segura de que ningún hombre puede admitir lo que somos capaces de hacer naturalmente sin pretender que ellos son los responsables (García Ponce 1995, 28).

En el fragmento recuerda su matrimonio, fallido por la incapacidad de su exesposo de verla tal cual era. Para facilitar su proceso de autodescubrimiento, Paloma será cómplice sexual de Gilberto, y él se apoyará en ella para afinar su mirada erótica y pensar el arte en su dimensión contemplativa, sin conocer el diario del otro. Al poco tiempo de comenzar a frecuentarse, Gilberto escribe:

La profundidad se encuentra en un secreto que el sexo hace aflorar, pero está más allá del sexo y permanece antes y después de su satisfacción al tiempo que su existencia se comprueba durante ella. Juntos, nuestros cuerpos son pura superficie y son insondables. No hay saciedad posible. Ni siquiera en el más extremo agotamiento. La superficie se convierte en un instrumento para llegar hasta algo que no se puede tocar y no obstante se encuentra presente en cada una de mis sensaciones, que se vuelven todas hacia ella y se confunden en ella, hasta el grado de que no parecen pertenecerme a mí sino a ella (García Ponce 1995, 42).

El conocimiento profundo de Paloma, desde la óptica de Gilberto, trasciende toda moral y da paso a la exploración de ese ser como una manifestación artística. Ésta es quizá la diferencia más radical entre ambas novelas: la comunicación erótica entre los dos personajes que desplaza lo sexual hacia 
una instancia trascendental y estética (Boodakian 2008, 41). El enfoque de García Ponce implica una revelación de Paloma y, si Gilberto obtiene algo, es la posibilidad de contemplarla desde la experiencia erótica, mientras que, en Tanizaki, el conocimiento interior es terreno exclusivo de Ikuko.

Paloma es el ánima que da título a la novela de García Ponce. Gilberto busca nociones estéticas que rebasen la dinámica de sus obras literarias y encontrará en ella la vía para encarnar una experiencia similar a la artística en el mundo real, aludiendo a esa corporalidad concreta, desde la que se estudia la entrega y la disolución del yo con marcados tintes místicos. Para Paloma, la entrega a sí misma — apoyada en la mirada de Gilberto- le permite desarrollar un conocimiento propio que no es exclusivamente intelectual, sino que se enraíza en el goce erótico y acaba en la misma experiencia trascendental, siempre encaminada hacia la luz:

Me miraba igual que Nicolás y no era exactamente la misma situación que antes cuando sólo era Nicolás quien me miraba, porque de ese modo se creaba una distancia diferente, pero también era perturbador [...] Mi amor se extendía sin límites, tocaba a Gilberto, a Nicolás, a cada uno de los muebles, a las paredes que cercaban la habitación y era también como la luz que cada vez más débil y tenue entraba por las ventanas y era un amor por Gilberto, era el amor entre Gilberto y yo que se extendía por el mundo y era parte de él (García Ponce 1995, 119-120; subrayado mío).

Este pasaje en particular alude a uno de los tantos terceros de la novela: al igual que en La llave con Kimura y Toshiko, el tercero de De ánima puede reubicarse: la mirada de Gilberto es un catalizador de la confianza de Paloma sobre sus propias sensaciones y la actitud abierta a su deseo, pero él puede ser remplazado por otros. Este fragmento muestra uno de los momentos clave en la novela: Nicolás Cusade, otro tercero, dibuja a Paloma para un cuento de Gilberto cuyo personaje femenino tomó como inspiración a Paloma. Ella es el centro de la historia, de las historias, los dibujos e incluso de una película: los diarios de ambos personajes avanzan a la par en el descubri- 
miento de ella misma mediante una escala de representatividad artística, del cuento al dibujo, de estos al cine. Ella se afianza en esa postura al hablar para sí cuando una amiga le advierte de las perversiones de Gilberto:

Mientras te oía hablar no dejé de preguntarme cuál sería el tamaño de tu escándalo si supieras que Gilberto ha convertido por encargo su cuento en un guión de cine, que éste va a filmarse, que yo asistí a su lectura sintiéndome retratada en cada uno de los gestos del personaje y en su descripción física, deseando ser la protagonista de las acciones que imaginó Gilberto y que al final de la lectura cedí a las súplicas del que va a ser director de la película y le encargó el guión a Gilberto de que pidiera un permiso en mi trabajo y aceptara representar al personaje que, en un sentido profundo, soy yo misma. Tu escándalo sería tan grande como el de mis padres (García Ponce 1995, 162).

El marco social está presente sólo para ser desafiado, para remarcar el carácter especial de la comunicación entre Paloma y Gilberto, opuesta a la de Ikuko y su marido, quienes seguían sosteniendo las apariencias, incapaces de mostrarse al otro. La complicidad de Gilberto y Paloma en el goce de Paloma resulta en la búsqueda de una luz que poco a poco profundiza en su dimensión estética. La apertura de ambos explica que sólo hacia el final Paloma tenga acceso al diario de Gilberto, es decir, que efectivamente García Ponce eligió sustituir la dinámica de fingimiento/acceso al diario del otro por una relación fuerte, asentada en la entrega y la libertad.

No obstante, los resultados de la comunicación no modifican el destino de los personajes masculinos. Gilberto no muestra síntomas de enfermedad - como el profesor de $\mathrm{La}$ llave- hasta el final de la novela, después de haber presenciado cómo Paloma se acostaba con el director de cine que la llevará a esa triple autorrepresentación. De alguna manera, ha sido desplazado físicamente y pasa a encarnar esa mirada desde fuera que tanto animó a Paloma. Una vez que Gilberto ha apoyado a Paloma para reconocerse, muere y la deja ser más allá de su mirada física, que seguirá siendo presencia en sus encuentros 
con otros. La posición de la mujer como ser que se descubre a partir del reconocimiento de sus propios deseos está en ambas novelas y, desde mi punto de vista, también marca los límites de la mirada y la posesión de sus parejas masculinas y las relega a un ámbito físico desde el cual observan el juego de luz y sombras que entraña el deseo.

\section{Conclusiones}

Como ha podido constatarse, la comparación entre De ánima y La llave arroja una lectura articulada desde dos estéticas complementarias. El análisis emprendido pone de relieve que el interés de Juan García Ponce por Japón no representa un préstamo limitado y superficial, como podría deducirse de una lectura apresurada de la mención de La llave en De ánima. Al contrario, se observa un diálogo en varios niveles textuales: va más allá de lo formal al apoyarse en otras lecturas que refuerzan sus criterios literarios; no es tan relevante el mero contacto asumido por García Ponce sino el diálogo literario que entabla con Tanizaki en torno al erotismo como puente entre dos tradiciones literarias.

Si bien la manera en que se lee y formula el erotismo en $D e$ ánima frente a La llave parte de las dificultades de traducción y difusión de la literatura japonesa para una comprensión más profunda de sus autores, García Ponce sortea el problema con una visión particular del arte y la literatura que le permite eludirlas al evitar las generalizaciones o los estereotipos culturales formulados por el orientalismo europeo e incluso por el modernismo latinoamericano. De ahí que busque elementos que añadir a su escritura, en aras de mantener un precario equilibrio entre el respeto por la otra cultura y su necesaria definición y contraste con la propia. Se desarrolla una voluntad horizontal que evita ejercer ese conjunto de categorías y conocimientos previos sobre Japón, en el intento de relacionarse con la cultura japonesa exclusivamente a través de sus textos. 
El autor mexicano opta por traer a Tanizaki a su terreno estético como un complemento, la sombra necesaria para mostrar la luz por contraste y así invita a que la otra cultura funja también como un tercero para dialogar sobre erotismo. Lo artístico se enriquece al formular un problema, como el de la comunicación en la pareja, que supera, en ambos casos, el nivel de las convenciones sociales o de las relaciones interpersonales, y apunta a la incomprensión o la inaccesibilidad del lenguaje erótico, en el que se proyectan múltiples significados, incluido el de la propia identidad. Con ello, García Ponce integra a Tanizaki a su escritura como esa mirada que es contrapunto del deseo en sí, de su expresión y de su manifestación artística.

\section{Referencias}

Arrieta Domínguez, Daniel. 2015. "Intertextualidad, dialogismo y poética cognitiva en la novela contemporánea: Bernardo Carvalho, Eduardo Lago y Mario Bellatín”. Tesis de doctorado. Universidad Complutense de Madrid. https://eprints.ucm.es/ $\mathrm{id} /$ eprint/33887/

Asiain, Aurelio, ed. 2014. Japón en Octavio Paz. México: Fondo de Cultura Económica.

Bataille, Georges. 1997 [1957]. El erotismo. Traducido por Antoni Vicens y Marie Paule Sarazin. Barcelona: Tusquets.

BATIs, Huberto. 1984. Lo que "Cuadernos del viento" nos dejó. México: Diógenes.

Boodakian, Florence Dee. 2008. Resisting Nudities. A Study in the Aesthetics of Eroticism. Nueva York: Peter Lang.

Cisneros, Odile. 2002. "El Oriente de dos mexicanos: Japón en la obra de Tablada y Rebolledo”. Literatura Mexicana 13 (2):91-116.

De la PeÑa, María Cristina. 2003. Imágenes del deseo. Estética en la obra de Juan García Ponce. México: Consejo Nacional para la Cultura y las Artes.

García Ponce, Juan. 1968. Entrada en materia. México: Universidad Nacional Autónoma de México. 
García Ponce, Juan. 1995 [1984]. De ánima. México: Joaquín Mortiz.

GenetTe, Gerard. 1989. Palimpsestos: la literatura en segundo grado. Traducido por Celia Fernández Prieto. Madrid: Taurus.

ITO, Ken K. 1991. Visions of Desire. Tanizaki's Fictional Worlds. Stanford, CA: Stanford University Press.

KIKUCHI, Yuko. 2004. Japanese Modernisation and Mingei Theory. Cultural Nationalism and Oriental Orientalism. Londres: RoutledgeCurzon. https://doi.org/10.4324/9780203644195

LEWIS, Reina. 1996. Gendering Orientalism: Race, Femininity and Representation. Nueva York: Routledge.

Long, Margherita. 2009. This Perversion Called Love: Reading Tanizaki, Feminist Theory, and Freud. Stanford, CA: Stanford University Press. https://doi.org/10.2307/j.ctvqsf120

Lowe, Lisa. 1991. Critical Terrains: French and British Orientalisms. Ithaca: Cornell University Press. https://doi.org/10.7591/ 9781501723124

Marion, Jean-Luc. 2005 [2003]. El fenómeno erótico. Seis meditaciones. Traducido por Silvio Mattoni. Buenos Aires: El Cuenco de Plata.

Nagy-Zekmi, Silvia, ed. 2008. Moros en la costa. Orientalismo en Latinoamérica. Madrid: Iberoamericana. https://doi.org/10.31819/ 9783964566065

OKakura, Kakuzō. 2018 [1903]. Los ideales de Oriente (con especial referencia al arte japonés). Traducido por Fernando Álvarez Rodríguez. Gijón: Satori.

Ота, Seiko. 2014. José Juan Tablada: su haikú y su japonismo. México: Fondo de Cultura Económica.

Pereira, Armando. 2019. "Juan García Ponce: entre el amor y el deseo". Literatura Mexicana 30 (2): 63-84. https://doi.org/10.19130/ iifl.litmex.30.2.2019.1182

QuARTUCCI, Guillermo. 1996. "Lo fantástico como reacción a la modernidad en Japón y México". Estudios de Asia y África 31 (2): 357-366. https://estudiosdeasiayafrica.colmex.mx/index. $\mathrm{php} / \mathrm{eaa} / \mathrm{article} / \mathrm{view} / 1556$

RosAdo, Juan Antonio. 2003. El engaño colorido. México: Universidad de la Ciudad de México.

SAdiq Jalal, Al-'Azm. 2000 [1981]. "Orientalism and Orientalism in Reverse". En Orientalism. A Reader, editado por Alexander 
Lyon Macfie, 217-238. Nueva York: New York University Press.

SAID, Edward. 2008 [1975]. Orientalismo. Traducido por María Luisa Fuentes. Barcelona: Mondadori.

Suzuki, Sadami. 1996. "Tanizaki Jun'ichirō as Cultural Critic”. Japan Review, núm. 7, 23-32. http://www.jstor.org/stable/ 25790963

TABOADA, Hernán G. H. 1998. "Un orientalismo periférico: viajeros latinoamericanos, 1786-1920”. Estudios de Asia y África 33 (2): 285-305. https://estudiosdeasiayafrica.colmex.mx/index.php/ eaa/article/view/1476

TANABE, Atsuko. 2004. "La literatura japonesa en México y la historia del Centro de Estudios Orientales de la Facultad de Filosofía y Letras de la UNAM". En Tiempo, historia y enseñanza: acercamiento a la metodología del historiador y al estudio del este de Asia, coordinado por Vera Valdés Lakowsky, 57-62. México: Universidad Nacional Autónoma de México.

TANIZAKI, Jun'ichirō. 1960 [1956]. The Key. Traducido por Howard Hibbett. Nueva York: Knopf.

TANIZAKI, Jun'ichirō. 2015 [1956]. Kagi 鍵. Tokio: Kyorinsya. Kindle. TANIZAKI, Jun'ichirō. 2016 [1956]. La llave. Traducido por Keiko Takahashi y Jordi Fibla. Barcelona: Siruela.

TANIZAKI, Jun'ichirō. 2018 [1933]. El elogio de la sombra. Traducido por Francisco Javier de Esteban Baquedano. Gijón: Satori.

Tinajero, Araceli. 2004. Orientalismo en el modernismo hispanoamericano. West Lafayette, IN: Purdue University Press.

TORres-Rodríguez, Laura. 2018. "Into the 'Oriental' Zone: Edward Said and Mexican Literature". En Mexican Literature in Theory, editado por Ignacio Sánchez Prado, 11-31. Nueva York: Bloomsbury.

WhitTingham, Georgina J. 2008. "El Japón de Hiroshigué en las pioneras innovaciones de José Juan Tablada”. En Moros en la costa. Orientalismo en Latinoamérica, editado por Silvia Nagy-Zekmi, 217-231. Madrid: Iberoamericana.

David Issai Saldaña Moncada es doctor en letras por la Universidad Nacional Autónoma de México y profesor de 
teoría literaria en la Facultad de Filosofía y Letras de la misma UNAM. Sus líneas de investigación son la parodia, la ironía, la metaficción y el orientalismo en la literatura latinoamericana y mexicana. Actualmente realiza una estancia posdoctoral con el proyecto "La construcción del vacío: ficciones y símbolos de lo japonés en la narrativa mexicana (1980-2015)", adscrito al Centro Regional de Investigaciones Multidisciplinarias de la UNAM.

https://orcid.org/0000-0001-9086-2138 saldana.david@crim.unam.mx 
